\title{
Net-exergetic, hydraulic and thermal optimization of coaxial heat exchangers using fixed flow conditions instead of fixed flow rates
}

\author{
Tobias Blanke ${ }^{1 *+} @$, Markus Hagenkamp ${ }^{1 \dagger}$, Bernd Döring ${ }^{1}$, Joachim Göttsche ${ }^{2}$, Vitali Reger ${ }^{3}$ and \\ Markus Kuhnhenne ${ }^{3}$
}

${ }^{*}$ Correspondence:

blanke@sij.fh-aachen.de

†Tobias Blanke and Markus

Hagenkamp contributed

equally to this work

${ }^{1}$ FH Aachen, Bayernallee 9,

52066 Aachen, Germany

Full list of author information

is available at the end of the article

\begin{abstract}
Previous studies optimized the dimensions of coaxial heat exchangers using constant mass flow rates as a boundary condition. They show a thermal optimal circular ring width of nearly zero. Hydraulically optimal is an inner to outer pipe radius ratio of 0.65 for turbulent and 0.68 for laminar flow types. In contrast, in this study, flow conditions in the circular ring are kept constant (a set of fixed Reynolds numbers) during optimization. This approach ensures fixed flow conditions and prevents inappropriately high or low mass flow rates. The optimization is carried out for three objectives: Maximum energy gain, minimum hydraulic effort and eventually optimum net-exergy balance. The optimization changes the inner pipe radius and mass flow rate but not the Reynolds number of the circular ring. The thermal calculations base on Hellström's borehole resistance and the hydraulic optimization on individually calculated linear loss of head coefficients. Increasing the inner pipe radius results in decreased hydraulic losses in the inner pipe but increased losses in the circular ring. The net-exergy difference is a key performance indicator and combines thermal and hydraulic calculations. It is the difference between thermal exergy flux and hydraulic effort. The Reynolds number in the circular ring is instead of the mass flow rate constant during all optimizations. The result from a thermal perspective is an optimal width of the circular ring of nearly zero. The hydraulically optimal inner pipe radius is $54 \%$ of the outer pipe radius for laminar flow and $60 \%$ for turbulent flow scenarios. Net-exergetic optimization shows a predominant influence of hydraulic losses, especially for small temperature gains. The exact result depends on the earth's thermal properties and the flow type. Conclusively, coaxial geothermal probes' design should focus on the hydraulic optimum and take the thermal optimum as a secondary criterion due to the dominating hydraulics.
\end{abstract}

Keywords: Geothermal heat exchanger, Annular, Coaxial, Hydraulic, Thermal, Netexergy, Optimization, Constant Reynolds number

\section{Introduction}

Steel pipes are a common option as a foundation for buildings on unstable ground (Hoback and Truman 1993). The boreholes must be drilled in such cases to ensure the static requirements of the building. It is reasonable to use them for geothermal purposes,

(c) The Author(s), 2021. Open Access This article is licensed under a Creative Commons Attribution 4.0 International License, which permits use, sharing, adaptation, distribution and reproduction in any medium or format, as long as you give appropriate credit to the original author(s) and the source, provide a link to the Creative Commons licence, and indicate if changes were made. The images or other third party material in this article are included in the article's Creative Commons licence, unless indicated otherwise in a credit line to the material. If material is not included in the article's Creative Commons licence and your intended use is not permitted by statutory regulation or exceeds the permitted use, you will need to obtain permission directly from the copyright holder. To view a copy of this licence, visit http:// creativecommons.org/licenses/by/4.0/. 
too. Steel pipes can be geothermally activated, for example, by using them as a single or double U geothermal probe (Gashti et al. 2014). Coaxial pipes are another option (Reger et al. 2019, 2020). The main advantages of coaxial pipes are a fully thermally activated steel pipe and avoidance of concrete use. Since static purposes design the steel pipe, it has fixed outer dimensions. So, improving options are limited to the inner pipe. In particular, the inner radius can serve as a primary parameter for thermal, hydraulic, and net-exergy optimization purposes. Net-exergy serves to combine thermal and hydraulic results.

Previous studies have determined the influence of inner pipe radius considering thermal (Iry and Rafee 2019; Zanchini et al. 2010) or hydraulic perspectives (Iry and Rafee 2019; Yekoladio et al. 2013). Thermal studies have shown that inner pipe radius and mass flow rate should be as big as possible (Iry and Rafee 2019; Zanchini et al. 2010). A hydraulic optimal inner pipe radius has been proposed to be about 0.65 times the outer pipe radius for turbulent flows (Iry and Rafee 2019; Yekoladio et al. 2013) and 0.68 for laminar flows (Yekoladio et al. 2013). Here, a constant mass flow rate is assumed, and different pipe surface roughnesses are neglected. One option to combine these influences is exergy. The combined research based on exergy has also been done (Alimonti et al. 2020; Yekoladio et al. 2013). This research has focused on the calculation of the exergy efficiency and not the optimization.

One problem with constant mass flow rates is that the Reynolds number corresponding to the optimal result cannot be determined beforehand. Therefore it is not clear whether the used calculation method for hydraulic losses is valid for the resulting Reynolds number. In this study, in contrast, optimization is based on a set of constant Reynolds numbers in the circular ring to ensure comparable flow conditions. Therefore, flow conditions are either laminar or turbulent in the circular ring, which ensures valid calculations. The mass flow rate is set to the minimum mass flow rate required. This setting ensures that the given flow conditions are fulfilled. Consequently, no unnecessary hydraulic loss is caused. The mass flow rate now depends on inner pipe radius and Reynolds number and is no longer constant during calculations.

Based on a constant Reynolds number, hydraulic effort, thermal heat fluxes, and net-exergy difference are optimized. As net-exergy, the thermal exergy flux minus the hydraulic effort (pure exergy) is considered. The net-exergy optimization is carried out to optimize thermal gains and hydraulic effort simultaneously. Since hydraulic or thermal optimum alone are not decisive, this allows the determination of a combined optimum. Improvements to the approach in existing literature are pointed out, especially for the hydraulic perspective. The influence of surface roughness on the hydraulic optimum is investigated additionally. Net-exergy is used to compare hydraulic and thermal results. The main innovation is a more general statement than in previous publications on the optimal dimensioning of coaxial heat exchangers based on comparable flow conditions.

\section{Methodology}

Figure 1 shows a sketch of a foundation pile with a coaxial heat exchanger and the corresponding geometric parameters. These are: an inner radius of inner pipe $\left(\overline{r_{i}}\right)$, an inner pipe thickness $(\delta)$, outer radius of inner pipe $\left(r_{i}\right)$, inner radius of outer pipe $\left(r_{a}\right)$ and outer pipe radius of outer pipe $\left(r_{o}\right)$ as well as thermal conductivity of inner pipe $\left(\lambda_{p}\right)$ and outer pipe $\left(\lambda_{c}\right)$. 


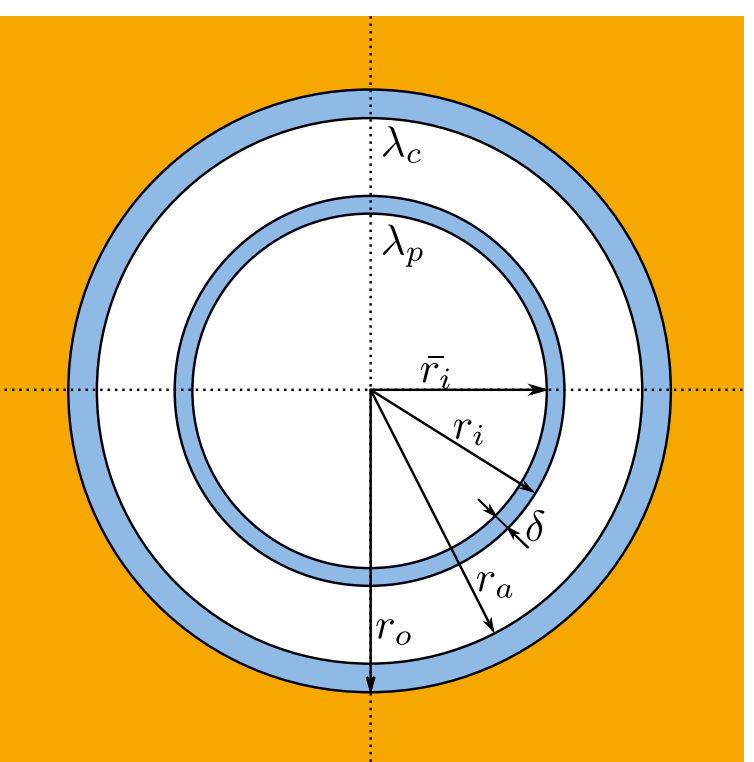

Fig. 1 Sketch of a coaxial geothermal heat exchanger with an outer radius of inner pipe $\left(r_{i}\right)$, an inner pipe thickness $(\delta)$, inner radius of inner pipe $\left(\bar{r}_{i}\right)$, an inner radius of outer pipe $\left(r_{a}\right)$ and an outer pipe radius of outer pipe $\left(r_{0}\right)$ as well as an inner pipe thermal conductivity $\left(\lambda_{p}\right)$ and an outer pipe thermal conductivity $\left(\lambda_{c}\right)$

Table 1 Used variables

\begin{tabular}{llll}
\hline Variables & Values & Units & Source \\
\hline$R e_{\text {lam }}$ & 1000 & {$[-]$} & (Kratz et al. 1931) \\
$\operatorname{Pr}$ & 26 & {$[-]$} & (pro 2016) \\
$\lambda_{\text {steel }}$ & 60 & {$[\mathrm{~W} /(\mathrm{m} \mathrm{K})]$} & $($ VDI 2010-06) \\
$\lambda_{\text {plastic }}$ & 0.42 & {$[\mathrm{~W} /(\mathrm{m} \mathrm{K})]$} & $($ VDI 2010-06) \\
$\lambda_{\text {brine }}$ & 0.513 & {$[\mathrm{~W} /(\mathrm{m} \mathrm{K})]$} & $($ pro 2016) \\
$k_{\text {steel }}$ & 2 & {$[\mathrm{~mm}]$} & $($ White 2011) \\
$k_{\text {plastic }}$ & 0.0015 & {$[\mathrm{~mm}]$} & $($ White 2011) \\
$\rho$ & 1036 & {$\left[\mathrm{~kg} / \mathrm{m}^{3}\right]$} & (pro 2016) \\
$v$ & $3.35 \times 10^{-6}$ & {$\left[\mathrm{~m}^{2} / \mathrm{s}\right]$} & (pro 2016) \\
$c_{p}$ & 3880 & {$[\mathrm{~J} /(\mathrm{kg} \mathrm{K})]$} & (pro 20) \\
$T_{e}$ & 10 & {$\left[{ }^{\circ} \mathrm{C}\right]$} & \\
\hline
\end{tabular}

In Table 1 the parameter values for all calculations are shown. To ensure the generalizability of the results dimensionless variables are defined. These are: a dimensionless inner radius $(c)$, a dimensionless mean inner radius $\left(c_{m}\right)$ and Standard Dimension Ratio (SDR) based on DIN (2011). They are defined as follows:

$$
\begin{aligned}
& c=\frac{r_{i}}{r_{a}} \\
& c_{m}=\frac{r_{i}-\frac{\delta}{2}}{r_{a}}
\end{aligned}
$$




$$
\mathrm{SDR}=\frac{2 \cdot r_{i}}{\delta}
$$

The Reynolds number for the circle ring $\left(R e_{c}\right)$ and inner pipe $\left(R e_{p}\right)$ are defined by the following equations (Nakayama and Boucher 1999a):

$$
\operatorname{Re}_{c}=\frac{v_{c} \cdot d_{\mathrm{hyd}, c}}{v}=\frac{\dot{m} \cdot 2 \cdot r_{a} \cdot(1-c)}{\rho \cdot v \cdot \pi \cdot\left(1^{2}-c^{2}\right) \cdot r_{a}^{2}}=\frac{2 \cdot \dot{m}}{\rho \cdot v \cdot \pi \cdot r_{a} \cdot(1+c)}
$$

using

$$
\begin{aligned}
& d_{\mathrm{hyd}, c}=2 \cdot\left(r_{a}-r_{i}\right) \\
& \operatorname{Re}_{p}=\frac{v_{p} \cdot d_{\mathrm{hyd}, p}}{v}=\frac{\dot{m} \cdot 2 \cdot r_{a} \cdot \frac{\overline{r_{i}}}{r_{a}}}{\rho \cdot v \cdot \pi \cdot r_{a}^{2} \cdot\left(\frac{\overline{r_{i}}}{r_{a}}\right)^{2}}=\frac{2 \cdot \dot{m}}{\rho \cdot v \cdot \pi \cdot r_{a} \cdot c \cdot\left(1-\frac{2}{\mathrm{SDR}}\right)}
\end{aligned}
$$

using

$$
d_{\mathrm{hyd}, p}=2 \cdot \overline{r_{i}}
$$

\section{Hydraulic optimization}

The objective of hydraulic optimization is to minimize power demand caused by hydraulic losses due to fluid friction. These hydraulic losses are directly dependent on the mass flow in the coaxial heat exchanger.

Power demand $\left(P_{\text {hydr }}\right)$ for a volume flow rate $(\dot{V})$ or mass flow rate $(\dot{m})$ in a coaxial heat exchanger with hydraulic losses $\left(\Delta p_{\text {coax }}\right)$ is defined as (Nakayama and Boucher $\left.1999 \mathrm{~b}\right)$ :

$$
P_{\text {hydr }}=\Delta p_{\text {coax }} \cdot \dot{V}=\Delta p_{\text {coax }} \cdot \frac{\dot{m}}{\rho}
$$

Hydraulic losses in the heat exchanger can be calculated based on Eq. 9 (Nakayama and Boucher 1999b):

$$
\Delta p_{\text {coax }}=\left[\frac{\Psi_{c}}{d_{\text {hyd }, c}} \cdot v_{c}^{2}+\frac{\Psi_{p}}{d_{\text {hyd }, p}} \cdot v_{p}^{2}\right] \cdot \frac{\rho}{2} \cdot L
$$

with

$\Psi_{p} \quad$ friction factor of inner pipe

$\Psi_{c} \quad$ friction factor of circular ring

$d_{\text {hyd, } p}$ hydraulic diameter of inner pipe

$d_{\text {hyd,c }}$ hydraulic diameter of circular ring

$v_{p} \quad$ fluid velocity in inner pipe

$v_{c} \quad$ fluid velocity in circular ring

$\rho \quad$ density of fluid

$L \quad$ length of geothermal pipe 
The resulting equation is with the hydraulic diameter (Eqs. 5 and 7) and the dependency between mass flow rate, cross-sectional area $\left(A=\pi \cdot r^{2}\right)$ and velocity $v\left(\nu=\frac{\dot{m}}{\rho \cdot A}\right)$ :

$$
\begin{aligned}
\Delta p_{\text {coax }}= & {\left[\frac{\Psi_{c}}{2 \cdot\left(r_{a}-r_{i}\right)} \cdot\left(\frac{\dot{m}}{\rho \cdot \pi \cdot\left(r_{a}^{2}-r_{i}^{2}\right)}\right)^{2}\right.} \\
& \left.+\frac{\Psi_{p}}{2 \cdot\left(r_{i}-\delta\right)} \cdot\left(\frac{\dot{m}}{\rho \cdot \pi \cdot\left(r_{i}-\delta\right)^{2}}\right)^{2}\right] \cdot \frac{\rho}{2} \cdot L
\end{aligned}
$$

Reynolds numbers of the circular ring are fixed at $R e_{c, \text { lam }}=1000$ for laminar flows based on Kratz et al. (1931) and $R e_{c \text {,turb }}=10000$ for turbulent flows based on VDI e.V. (2010) to ensure a good thermal response. The mass flow rate as a function of Reynolds number can be calculated with:

$$
\begin{aligned}
\operatorname{Re}_{c} & =\frac{v_{c} \cdot d_{\mathrm{hyd}, c}}{v}=\frac{\frac{\dot{m}}{\rho \cdot \pi \cdot\left(r_{a}^{2}-r_{i}^{2}\right)} \cdot 2 \cdot\left(r_{a}-r_{i}\right)}{v}=\frac{2 \cdot \dot{m}}{\rho \cdot \pi \cdot v \cdot\left(r_{a}+r_{i}\right)} \\
\Leftrightarrow & \dot{m}=\frac{\operatorname{Re}_{c} \cdot \rho \cdot \pi \cdot v \cdot\left(r_{a}+r_{i}\right)}{2}
\end{aligned}
$$

Hydraulic losses can be calculated using the resulting mass flow rate (Eq. 11) in Eq. 10:

$$
\begin{aligned}
\Delta p_{\text {coax }}= & {\left[\frac{\Psi_{c}}{2 \cdot\left(r_{a}-r_{i}\right)} \cdot \frac{\rho}{2} \cdot\left(\frac{R e_{c} \cdot \rho \cdot \pi \cdot v \cdot\left(r_{a}+r_{i}\right)}{2 \cdot \rho \cdot \pi \cdot\left(r_{a}^{2}-r_{i}^{2}\right)}\right)^{2}\right.} \\
& \left.\quad+\frac{\Psi_{p}}{2 \cdot\left(r_{i}-\delta\right)} \cdot \frac{\rho}{2} \cdot\left(\frac{R e_{c} \cdot \rho \cdot \pi \cdot v \cdot\left(r_{a}+r_{i}\right)}{2 \cdot \rho \cdot \pi \cdot\left(r_{i}-\delta\right)^{2}}\right)^{2}\right] \cdot L \\
= & {\left[\frac{\rho \cdot\left(R e_{c} \cdot v\right)^{2}}{16}\left(\frac{\Psi_{p} \cdot\left(r_{a}+r_{i}\right)^{2}}{\left(r_{i}-\delta\right)^{5}}+\frac{\Psi_{c}}{\left(r_{a}-r_{i}\right)^{3}}\right)\right] \cdot L }
\end{aligned}
$$

The resulting power demand is:

$$
\begin{aligned}
P & =\Delta p_{\text {coax }} \cdot \dot{V} \\
& =\left[\frac{\rho \cdot L \cdot\left(R e_{c} \cdot v\right)^{2}}{16}\left(\frac{\Psi_{p} \cdot\left(r_{a}+r_{i}\right)^{2}}{\left(r_{i}-\delta\right)^{5}}+\frac{\Psi_{c}}{\left(r_{a}-r_{i}\right)^{3}}\right)\right] \cdot \frac{\frac{R e_{c}}{2} \cdot \rho \cdot \pi \cdot v \cdot\left(r_{a}+r_{i}\right)}{\rho}
\end{aligned}
$$

The equation can be simplified using dimensionless inner pipe radius $(c)$ and Standard Dimension Ratio (SDR):

$$
P=\frac{\rho \cdot \pi \cdot L \cdot\left(R e_{c} \cdot v\right)^{3}}{32 \cdot r_{a}^{2}} \cdot\left(\frac{\Psi_{p} \cdot(1+c)^{3}}{c^{5} \cdot\left(1-\frac{2}{\mathrm{SDR}}\right)^{5}}+\frac{\Psi_{c} \cdot(1+c)}{(1-c)^{3}}\right)
$$

Density $(\rho)$, critical Reynolds number $\left(R e_{c}\right)$, kinematic viscosity $(v)$ and outer pipe radius $\left(r_{a}\right)$ are assumed to be constant: 


$$
P=C \cdot\left(\frac{\Psi_{p} \cdot(1+c)^{3}}{c^{5} \cdot\left(1-\frac{2}{\mathrm{SDR}}\right)^{5}}+\frac{\Psi_{c} \cdot(1+c)}{(1-c)^{3}}\right)
$$

With these assumptions a dimensionless power factor $(K)$ can be defined:

$$
K:=\frac{P}{C}=\frac{\Psi_{p} \cdot(1+c)^{3}}{c^{5} \cdot\left(1-\frac{2}{\mathrm{SDR}}\right)^{5}}+\frac{\Psi_{c} \cdot(1+c)}{(1-c)^{3}}
$$

Minimizing the dimensionless power factor $(K)$ is sufficient to minimize power demand. Consequently, Eq. 17 defines the final objective function for the hydraulic minimization problem.

$$
\min [K(c)]_{\forall c \in(0,1)}=\min \left[\frac{\Psi_{p} \cdot(1+c)^{3}}{c^{5} \cdot\left(1-\frac{2}{\mathrm{SDR}}\right)^{5}}+\frac{\Psi_{c} \cdot(1+c)}{(1-c)^{3}}\right]_{\forall c \in(0,1)}
$$

The derivative of the objective function results in a polynomial function of grade 6 . An analytical solution to the minimization problem is impractical. A numerical approach is chosen based on a Sequential Quadratic Programming (SQP) algorithm implemented in Matlab's 'fmincon' function (Mat 2019). More information on SQP as one of the most effective methods for nonlinearly constrained optimization problems" can be found in Boggs and Tolle (2000) and Daras (2012). A Matlab script is set up to evaluate the optimization problem for several parameter sets (see Table 4 for all scenarios).

Initial value of $c$ for minimization in all scenarios is set to $c_{0}=0.9$. This value is nearly the end of the valid range and resulting in good gradients for minimization.

The friction factors are unknown. Three cases are evaluated to estimate possible values. These cases are laminar flow (laminar), turbulent flow outside rough regime (turb.), and rough regime turbulent flow (turb. r.r.).

For the laminar flow case the friction factors for pipe $\left(\Psi_{p}\right)$ and circular $\operatorname{ring}\left(\Psi_{c}\right)$ are defined according to White (2011) as:

$$
\begin{aligned}
& \Psi_{p}=\frac{64}{R e_{p}} \\
& \Psi_{c}=\frac{64}{R e_{c}} \cdot \frac{(1-c)^{2} \cdot\left(1-c^{2}\right)}{1-c^{4}-\frac{\left(1-c^{2}\right)^{2}}{\ln (1 / c)}}
\end{aligned}
$$

Ratio of the Reynolds numbers for pipe $\left(R e_{p}\right)$ and circle ring $\left(R e_{c}\right)$ can be formulated as:

$$
\frac{R e_{c}}{R e_{p}}=\frac{c \cdot\left(1-\frac{2}{\mathrm{SDR}}\right)}{1+c}
$$

The resulting minimization function by inserting Eqs. 18 and 19 in 17 is: 


$$
\begin{aligned}
& \min [K(c)]_{\forall c \in(0,1)} \\
= & \min \left[\frac{(1+c)^{2}}{c^{4}\left(1-\frac{2}{\mathrm{SDR}}\right)^{4}}+\frac{(1+c)}{(1-c)^{3}} \cdot \frac{(1-c)^{2} \cdot\left(1-c^{2}\right)}{1-c^{4}-\frac{\left(1-c^{2}\right)^{2}}{\ln \left(\frac{1}{c}\right)}}\right]_{\forall c \in(0,1)}
\end{aligned}
$$

For turbulent flows in the circular ring and inner pipe the friction factor can be calculated with (Moody and Princeton 1944):

$$
\begin{aligned}
& \frac{1}{\sqrt{\Psi}}=-2 \cdot \log \left(\frac{2.51}{R e \cdot \sqrt{\Psi}}+\frac{k}{3.72 \cdot d_{\mathrm{hyd}}}\right) \quad \text { (outside rough regime) } \\
& \frac{1}{\sqrt{\Psi}}=-2 \cdot \log \left(\frac{k}{3.72 \cdot d_{\mathrm{hyd}}}\right) \quad \text { (in rough regime) }
\end{aligned}
$$

The hydraulic diameters can be written as a function of the inner radius of the outer pipe $\left(r_{a}\right)$ :

$$
\begin{aligned}
& d_{\mathrm{hyd}, p}=\left(1-\frac{2}{\mathrm{SDR}}\right) \cdot c \cdot 2 \cdot r_{a} \\
& d_{\mathrm{hyd}, c}=(1-c) \cdot 2 \cdot r_{a}
\end{aligned}
$$

Surface roughness of inner pipe $\left(k_{p}\right)$ and outer pipe $\left(k_{a}\right)$ are used to define a medium surface roughness $\left(k_{c}\right)$ for the circular ring. This is based on circumference:

$$
k_{c}:=\frac{k_{a} \cdot 2 \pi \cdot r_{a}+k_{p} \cdot 2 \pi \cdot r_{i}}{2 \pi \cdot\left(r_{a}+r_{i}\right)}=\frac{k_{a}+c \cdot k_{p}}{1+c}
$$

An iterative solution of Eq. 22 for $\Psi$ is necessary to formulate friction factors outside the rough regime. It is carried out programmatically. In both cases, the resulting friction factors can be used in Eq. 17 to complete the objective function for the optimization.

For hydraulic calculations, a reference case (Index st.) is defined based on Reger et al. (2020). To analyze sensitivities, every parameter in the reference case is varied. Parameter values and variation ranges can be found in Table 2. Values for SDR are chosen according to EN 12201-2 (DIN 2011).

The equations of Yekoladio et al. (2013) are extended with an SDR term to compare the new results with those using a fixed mass flow rate. The optimization is performed for these equations as well. The resulting equation for laminar flow types is:

$$
K(c)=\frac{\frac{1-c}{1+c}}{1-c^{4}-\frac{\left(1-c^{2}\right)^{2}}{\ln \left(\frac{1}{c}\right)}}+\frac{1}{c^{4} \cdot\left(1-\frac{2}{\mathrm{SDR}}\right)^{4}}
$$

The resulting equation for turbulent flow types is: 
Table 2 Overview of modified parameters and variation range for hydraulic optimization

\begin{tabular}{|c|c|c|c|c|}
\hline Parameters & Unit & Reference case(st.) & Range/variation & Abbreviations \\
\hline$r_{i}$ & {$[\mathrm{~m}]$} & - & {$[0.01: 0.99]$} & \\
\hline \multirow[t]{2}{*}{ SDR } & {$[-]$} & 11 & 67.491113 .6 & \\
\hline & & & 1721263341 & \\
\hline \multirow[t]{2}{*}{ flow type } & {$[-]$} & Turbulent & Laminar & \\
\hline & & & Turbulent rough regime & \\
\hline \multirow[t]{3}{*}{$\operatorname{Re}$} & {$[-]$} & 10000 & 1000 & $R e_{c, l a m}$ \\
\hline & & & 4000 & $R e_{c, \min }$ \\
\hline & & & 100000 & $R e_{c, \max }$ \\
\hline \multirow[t]{2}{*}{ L } & {$[\mathrm{m}]$} & 20 & 5 & $L_{\min }$ \\
\hline & & & 100 & $L_{\max }$ \\
\hline \multirow[t]{2}{*}{$r_{a}$} & {$[\mathrm{~m}]$} & 75 & 39 & $r_{a, \min }$ \\
\hline & & & 240 & $r_{a, \max }$ \\
\hline \multirow[t]{3}{*}{ k } & {$[-]$} & Plastic/steel & Steel/plastic & $k_{\text {switch }}$ \\
\hline & & & Steel/steel & $k_{\text {steel }}$ \\
\hline & & (Inner pipe/outer pipe) & Plastic/plastic & $k_{\text {plast }}$ \\
\hline
\end{tabular}

$$
K(c)=\frac{\Psi_{c}}{(1-c)^{3} \cdot(1+c)^{2}}+\frac{\Psi_{p}}{c^{5} \cdot\left(1-\frac{2}{\mathrm{SDR}}\right)^{5}}
$$

According to Yekoladio et al. (2013) both friction factors $\left(\Psi_{c}, \Psi_{p}\right)$ are set to 1.

\section{Thermal calculations}

The concept of borehole resistances by Hellström is used for thermal calculations (Hellström 1991). This concept is used because of its less complexity and the ability to neglect earth properties. These properties are neglected since the earth properties are not depending on the inner pipe dimensions.

The first considered resistance is internal borehole resistance $\left(R_{a}\right)$ to model thermal short circuit heat transfer. The second resistance is the borehole resistance $\left(R_{b}\right)$ as an indicator for collected heat from the ground. Hellström (1991) defines the internal borehole resistance $R_{a}$ for coaxial geothermal pipes as:

$$
R_{a}=\frac{1}{2 \cdot \pi \cdot c \cdot\left(1-\frac{2}{\mathrm{SDR}}\right) \cdot r_{a} \cdot \alpha_{i}(c)}+\frac{\ln \left(\frac{1}{1-\frac{2}{\mathrm{SDR}}}\right)}{2 \cdot \pi \cdot \lambda_{p}}+\frac{1}{2 \cdot \pi \cdot c \cdot r_{a} \cdot \alpha_{o}(c)}
$$

Borehole resistance $R_{b}$ is defined by Hellström (1991):

$$
R_{b}=\frac{1}{2 \cdot \pi \cdot r_{a} \cdot \alpha_{o}(c)}+\frac{\ln \left(\frac{r_{o}}{r_{a}}\right)}{2 \cdot \pi \cdot \lambda_{c}}
$$

Total borehole resistance $\left(R_{b}^{*}\right)$ combines both influences and is defined by Gehlin (2002); Huber (2018) as follows: 


$$
R_{b}^{*}(c)=R_{b}(c)+\frac{L^{2}}{3 \cdot R_{a}(c) \cdot \dot{m}(c)^{2} \cdot c_{p}^{2}}
$$

with $L$ as borehole depth, mass flow rate $\dot{m}$ and heat capacity $c_{p} . \alpha_{i}$ and $\alpha_{o}$ are the convective heat transfer coefficients of the inner pipe and circular ring.

Best thermal performance corresponds to the lowest total borehole resistance $\left(R_{b}^{*}\right)$ since there are no other ways of heat transmission (radiation, further convective processes...) to be considered. Convective heat transfer coefficients are calculated by using Nusselt number $\mathrm{Nu}$ (VDI e.V. 2010):

$$
N u_{k}=\frac{\alpha_{k} \cdot d_{\mathrm{hyd}, k}}{\lambda}
$$

with the hydraulic diameter $d_{\mathrm{hyd}, k}$ for $k \in\{c, p\}$ and the thermal conductivity of the fluid $\lambda$.

The Nusselt number calculation differs between laminar flow and turbulent flow and between pipes and circular rings. Nusselt number is calculated according to Gnielinski (VDI e.V. 2010). Nusselt depends on Prandtl number (Pr), Reynolds number, inner to outer pipe radius ratio, different radii, and the borehole length.

Similar to the hydraulic calculations a range of variations is carried out for sensitivity and validation purposes (see Table 3).

These calculations are also performed for a fixed mass flow rate to compare the new approach to the old one. Therefore the mass flow rate for a dimensionless inner radius (c) of 0.5 is calculated and set constant.

\begin{tabular}{|c|c|c|c|c|}
\hline Parameters & Units & Reference case (st.) & Range/variation & Abbreviations \\
\hline$r_{i}$ & {$[\mathrm{~m}]$} & - & {$[0.01: 0.99]$} & \\
\hline \multirow[t]{2}{*}{ SDR } & {$[-]$} & 11 & 6 & \\
\hline & & & 41 & \\
\hline \multirow[t]{2}{*}{ flow type } & {$[-]$} & Turbulent (turb.) & Laminar & \\
\hline & & & Turb. r. r. (rough regime) & \\
\hline \multirow[t]{3}{*}{$\lambda$} & {$[\mathrm{W} /(\mathrm{m} \mathrm{K})]$} & Plastic/steel & Steel/plastic & $\lambda_{\text {switch }}$ \\
\hline & & & Steel / steel & $\lambda_{\text {steel }}$ \\
\hline & & (Inner/outer pipe) & Plastic / plastic & $\lambda_{\text {plast }}$ \\
\hline \multirow[t]{2}{*}{$r_{a}$} & {$[\mathrm{~mm}]$} & 75 & 39 & $r_{a, \min }$ \\
\hline & & & 240 & $r_{a, \max }$ \\
\hline \multirow[t]{2}{*}{$r_{0}$} & {$[\mathrm{~mm}]$} & 85 & 45 & $r_{0, \min }$ \\
\hline & & & 250 & $r_{0, \max }$ \\
\hline \multirow[t]{2}{*}{ L } & {$[\mathrm{m}]$} & 20 & 5 & $L_{\min }$ \\
\hline & & & 100 & $L_{\max }$ \\
\hline \multirow[t]{3}{*}{ Re } & {$[-]$} & 10000 & 1000 & $R e_{c, l a m}$ \\
\hline & & & 4000 & $\operatorname{Re}_{c, \min }$ \\
\hline & & & 100000 & $R e_{c, \max }$ \\
\hline
\end{tabular}

Table 3 Overview of modified parameters and variation range for thermal calculations 


\section{Exergy difference maximization}

In practical applications, thermal effects cannot be adequately evaluated if hydraulic effects are neglected and vice versa. For a combined analysis, exergy is an appropriate indicator.

An exergy optimization is carried out using exergy balance by Alibaba et al. (2020) using a logarithmic mean temperature difference (Mistry and Misener 2016):

$$
\max \left(\dot{E}_{e x}\right)_{\forall c \in(0,1)}=\max \left(\left(1-\frac{T_{e} \cdot \ln \left(\frac{T_{\text {in }}}{T_{\text {out }}}\right)}{T_{\text {in }}-T_{\text {out }}}\right) \cdot \dot{Q}_{g e o}-P_{\text {hydr }}\right)_{\forall c \in(0,1)}
$$

Hydraulic power $\left(P_{\text {hydr }}\right)$ is calculated as explained in section hydraulic optimization. Heat flux $\left(\dot{Q}_{g e o}\right)$ and outlet temperature $\left(T_{\text {out }}\right)$ are calculated as explained in Eq. 34 and 36 , respectively. Earth temperature $\left(T_{e}\right)$ is assumed to be $10^{\circ} \mathrm{C}$ and inlet temperature $\left(T_{i n}\right)$ depends on the considered case explained later. $10^{\circ} \mathrm{C}$ is the yearly average ambient temperature for many locations in Germany (AM Online Projects 2021). Temperature gradient over depth of typically $3 \mathrm{~K}$ per $100 \mathrm{~m}$ is neglected, because in the proposed applications the probe length is typically limited to $100 \mathrm{~m}$.

The heat flux of coaxial heat exchanger is defined as difference in enthalpy flow of inlet and outlet (VDI e.V. 2010):

$$
\dot{Q}_{\text {geo }}=\dot{m} \cdot c_{p} \cdot\left(T_{\text {in }}-T_{\text {out }}\right)
$$

The heat flux entering the system must equal the heat flux leaving the system, considering a stationary system. $\dot{Q}_{g e o}$ can therefore be calculated based on Hellström (1991) with a linearized fluid temperature. Resulting error is less than $10^{-6}$ compared to a logarithmic temperature:

$$
\dot{Q}_{\text {geo }}=\frac{L \cdot\left(\frac{T_{\text {in }}+T_{\text {out }}}{2}-T_{e}\right)}{R_{b}^{*}+R_{g}}
$$

with $R_{g}$ as thermal ground resistance and $R_{b}^{*}$ as total borehole resistance calculated as explained in section thermal calculations. Combining Eqs. 34 and 35 yields to:

$$
T_{\text {out }}=\frac{\left(\dot{m} \cdot c_{p}-\frac{L}{2 \cdot\left(R_{b}^{*}+R_{g}\right)}\right) \cdot T_{i n}+\frac{L}{R_{b}^{*}+R_{g}} \cdot T_{e}}{\dot{m} \cdot c_{p}+\frac{L}{2 \cdot R}}
$$

The optimization uses the same optimizing algorithm as in section hydraulic optimization. Starting point is $c=0.8$. Calculation is done for SDR values from 6 to 41 and thermal ground resistance $\left(R_{g}\right)$ values from $0.05 \mathrm{~m} \mathrm{~K} / \mathrm{W}$ to $0.3 \mathrm{~m} \mathrm{~K} / \mathrm{W}$. An inlet temperature difference above earth temperature of $\Delta T=T_{i n}-T_{e}=5 \mathrm{~K}$ and $\Delta T=20 \mathrm{~K}$ is assumed for laminar flows. $\Delta T=20 \mathrm{~K}$ as well as $\Delta T=50 \mathrm{~K}$ above earth temperature is assumed for turbulent flows.

These calculations for an $\Delta T=20 \mathrm{~K}$ are also performed for a fixed mass flow rate. Therefore the mass flow rate for a dimensionless inner radius $(c)$ of 0.5 is calculated and set constant. Furthermore, the hydraulic calculation of Yekoladio et al. (2013) is considered extended by an SDR term. 


\section{Results and discussion \\ Hydraulic results}

Figure 4 shows the hydraulic results. In contrast to thermal considerations ("Thermal results" section) the hydraulic optimization results in an optimal ratio $(c)$. These results can be explained by increasing hydraulic losses in the circular ring for large values of $c$ and increasing hydraulic losses in the inner pipe for low values of $c$. For a given Reynolds number and the determined optimal $c$, Eq. 11 yields the corresponding optimal mass flow rate $\dot{m}$.

\section{$S D R$}

Results in Fig. 2a show a reciprocally proportional decreasing optimal inner to outer pipe ratio $\left(c_{\text {opt }}\right)$ with an increasing Standard Dimension Ratio (SDR). This decrease is partly since dimensionless inner pipe radius $c_{\text {opt }}$ is defined as the inner pipe's outer radius. So, when inner pipe thickness decreases (SDR increase), the outer radius of the inner pipe decreases as well. Subtracting half of the dimensionless pipe thickness from $c_{\text {opt }}$ yields $c_{m, \mathrm{opt}}$ as a measurement for the inner pipe's middle radius. Figure 2a shows that the dimensionless middle radius of the inner pipe increases with SDR for turbulent flows. In all cases, it converges towards the outer radius of the inner pipe for very high SDR values or small pipe thicknesses. For SDR values close to 2 (inner pipe thickness close to $\left.r_{i}\right), c_{m, \text { opt }}$ converges towards 0.5 in all scenarios, meaning that the middle radius of inner pipe is $r_{a} / 2$ and the inner pipe completely fills the room in the outer pipe $\left(r_{i}=r_{a}\right)$. In practice, only the outer radius of the inner pipe is compared. Therefore, the following examinations consider only $c_{\mathrm{opt}}$.

\section{Flow type}

Laminar flows result in an optimal inner to outer pipe ratio $\left(c_{\mathrm{opt}}\right)$ of ca. 0.55 for high Standard Dimension Ratios (SDR), for turbulent flows the ratio is ca. 0.62 and for rough regime turbulent flows it is ca. 0.61 . As discussed in "Thermal results" section, the Reynolds number in the inner pipe decreases with increasing $c$. The fact that $c_{\mathrm{opt}}$ is lower for more turbulent flow types suggests that it is advantageous to transfer the Reynolds number increase of the circular ring to the inner pipes Reynolds number.

\section{Material roughness}

Figure $2 \mathrm{~b}$ plots the optimal dimensionless inner radius $c$ over SDR. The figure shows the optimal dimensionless inner radius for the flow types rough regime turbulent flow and turbulent flow and all possible material combinations. For turbulent flow types, the same pipe material on outer and inner pipe results for plastics in a lower optimal $c$ than steel. When two different materials are combined, the optimum radius is not between individual materials' optima. Instead, the optimum in the standard case (i.e. plastic as inner pipe material) shifts significantly towards smaller radii than the optima of sole steel or plastic set-ups. Besides, the optimum shifts towards larger radii for the switched case (with steel as inner pipe material). This shift can be explained by the following connection:

Equation 26 defines the circular ring's roughness as a mean roughness in between both materials roughnesses. When the material for the inner pipe has a low roughness 

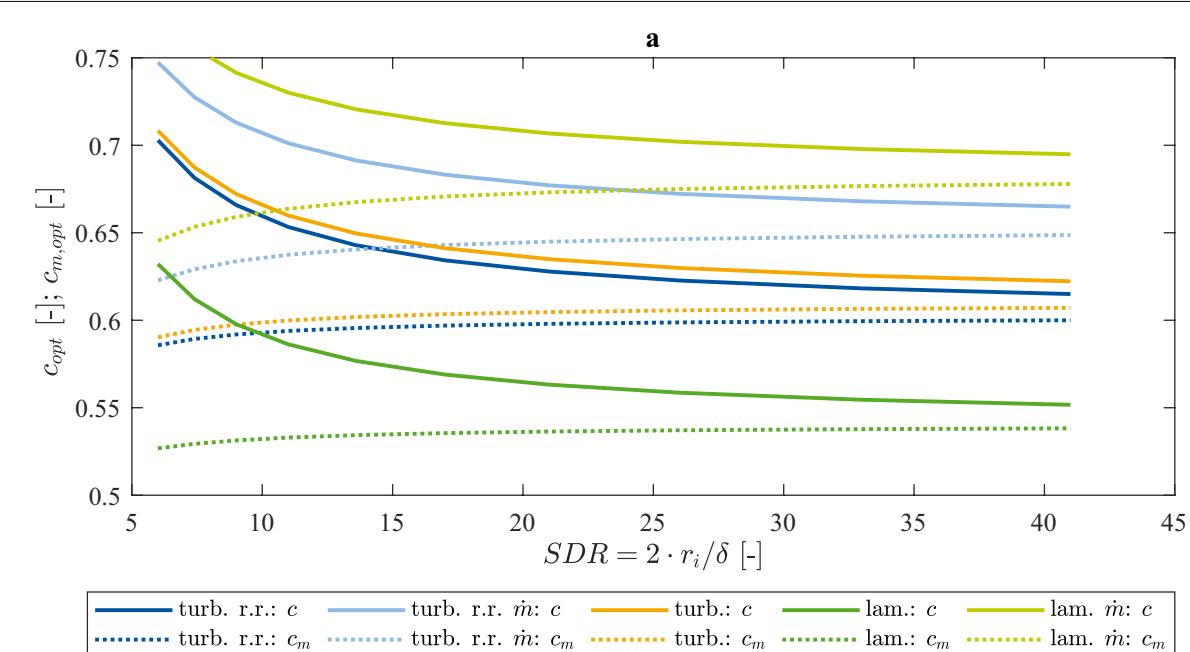

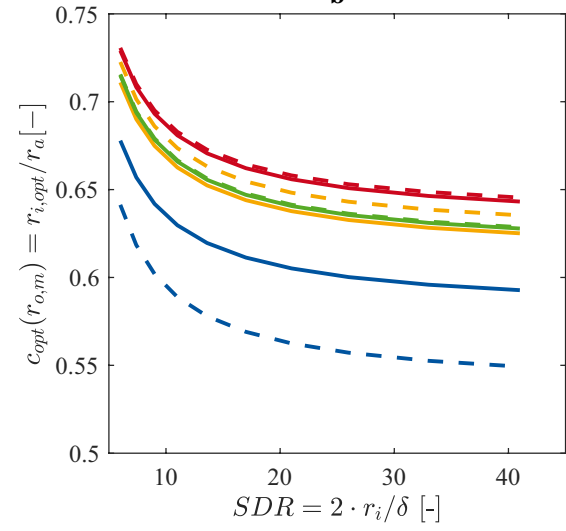

$$
\begin{array}{|l|}
\hline- \text { standard M. turb. } \\
\hline- \text { standard M. turb. r.r. } \\
-- \text { plastic M. .. turb. } \\
\hline \text { plastic M. .. turb. r.r. } \\
-\quad \text { steel M. .... turb. } \\
- \text { steel M. .... turb. r.r. } \\
- \text { - switched M. turb. } \\
\text { - switched M. turb. r.r. }
\end{array}
$$

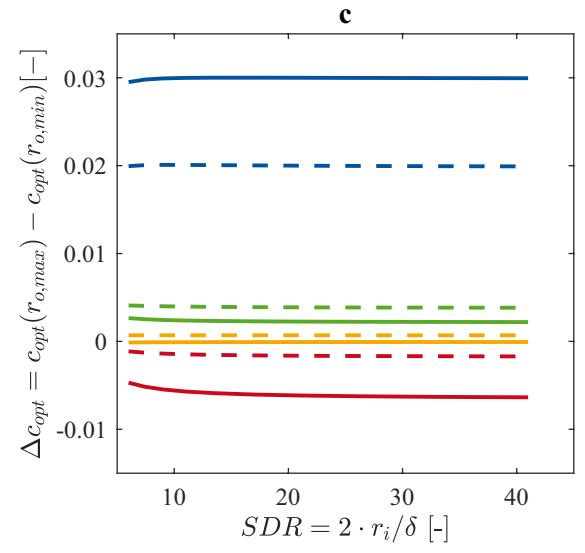

Fig. 2 Results of hydraulic optimization (a Influence of flow type and SDR, b Influence of material, c Influence outer pipe radius) Influence of several parameters on optimal hydraulic results for laminar and turbulent flows a Optimal inner pipe radius $C_{o p t}$ as well as optimal inner pipe middle radius $C_{m, o p t}$ for different flow types over standard dimension ratio SDR for fixed Reynolds numbers and fixed mass flow rates ( $\dot{m})$. Reference case. b Optimal inner pipe radius $c_{\text {opt }}$ calculated with the smallest outer pipe radius $r_{0, \text { min }}$ for all material combinations over SDR $\mathbf{c}$ Deviation $\Delta c_{\text {opt }}$ of optimal inner pipe radius from the results in $b$ when calculating with the largest outer pipe radius $r_{0, \max }$ for all material combinations over SDR

(plastic or standard case), the inner pipe's roughness is certainly less than in the circular ring. On the other hand, the circular ring's roughness is less than in the inner pipe when the inner pipe consists of steel (switched case). The optimal dimensionless inner radius shifts to increase the hydraulic diameter for the section with higher material roughness for different materials. By doing so, the influence of wall roughness on the overall flow reduces. This reduction is because wall roughness only affects flow regions close to the surface. Also, the shift increases the velocity in the section with low wall friction and reduces it in the area with higher friction. Different pipe 
materials' influence is more significant in rough regime turbulent flows since friction losses are higher than in only turbulent flows.

\section{Outer pipe radius}

Results in Table 4 and Figure 2c show that the outer pipe's outer radius does not significantly influence the optimal dimensionless inner pipe radius. When the inner and outer pipe consist of the same material, the change in $c$ resulting from different outer pipe radii does not exceed 0.004. Where the materials of inner and outer pipe differ, there is a small shift of $c$ (maximum: $\Delta c=0,03$ ). For steel as outer pipe material (standard case), this effect is directed towards bigger radii for bigger outer pipe radii. In case the outer pipe consists of plastic (switched case), the shift is smaller and directed towards smaller radii.

In the switched case, the quotient of the friction factors $\Psi_{p} / \Psi_{c}$ decreases very slightly towards 1 (equal friction factors in inner pipe and circular ring) with increasing $r_{a}$. Consequently, the influence of roughness on optimal radius decreases as well. For the standard case, $\Psi_{p} / \Psi_{c}$ increases slightly from below 1 towards equal friction

Table 4 Hydraulic results as optimal dimensionless inner pipe ratio over different Standard Dimension Ratios (SDR) and different cases

\begin{tabular}{|c|c|c|c|c|c|c|c|c|c|c|c|}
\hline \multirow[t]{2}{*}{ Mat. } & \multirow[t]{2}{*}{$r_{a}$} & \multicolumn{10}{|l|}{ SDR } \\
\hline & & 6 & 7.4 & 9 & 11 & 13.6 & 17 & 21 & 26 & 33 & 41 \\
\hline & & \multicolumn{10}{|c|}{ Laminar } \\
\hline & - & 0.6321 & 0.6121 & 0.5977 & 0.5862 & 0.5767 & 0.5690 & 0.5632 & 0.5586 & 0.5546 & 0.5517 \\
\hline & & \multicolumn{10}{|c|}{ Turbulent } \\
\hline \multirow[t]{3}{*}{ Plastic } & $r_{\min }$ & 0.7111 & 0.6901 & 0.6749 & 0.6627 & 0.6524 & 0.6440 & 0.6378 & 0.6327 & 0.6283 & 0.6252 \\
\hline & $r_{m}$ & 0.7110 & 0.6901 & 0.6749 & 0.6626 & 0.6524 & 0.6440 & 0.6377 & 0.6327 & 0.6283 & 0.6251 \\
\hline & $r_{\max }$ & 0.7109 & 0.6900 & 0.6748 & 0.6626 & 0.6523 & 0.6439 & 0.6377 & 0.6327 & 0.6283 & 0.6251 \\
\hline \multirow[t]{3}{*}{ Steel } & $r_{\min }$ & 0.7134 & 0.6923 & 0.6769 & 0.6645 & 0.6542 & 0.6456 & 0.6393 & 0.6342 & 0.6297 & 0.6265 \\
\hline & $r_{m}$ & 0.7149 & 0.6938 & 0.6784 & 0.6659 & 0.6556 & 0.6470 & 0.6407 & 0.6355 & 0.6311 & 0.6278 \\
\hline & $r_{\max }$ & 0.7161 & 0.6948 & 0.6794 & 0.6669 & 0.6565 & 0.6479 & 0.6415 & 0.6364 & 0.6319 & 0.6287 \\
\hline \multirow[t]{3}{*}{ Stand. } & $r_{\min }$ & 0.6651 & 0.6441 & 0.6289 & 0.6167 & 0.6066 & 0.5983 & 0.5921 & 0.5872 & 0.5828 & 0.5797 \\
\hline & $r_{m}$ & 0.6779 & 0.6570 & 0.6419 & 0.6297 & 0.6196 & 0.6113 & 0.6052 & 0.6002 & 0.5959 & 0.5928 \\
\hline & $r_{\max }$ & 0.6946 & 0.6739 & 0.6588 & 0.6467 & 0.6366 & 0.6283 & 0.6221 & 0.6172 & 0.6128 & 0.6097 \\
\hline \multirow[t]{4}{*}{ Switch } & $r_{\min }$ & 0.7303 & 0.7097 & 0.6946 & 0.6824 & 0.6723 & 0.6639 & 0.6576 & 0.6526 & 0.6481 & 0.6450 \\
\hline & $r_{m}$ & 0.7291 & 0.7083 & 0.6931 & 0.6809 & 0.6706 & 0.6622 & 0.6559 & 0.6508 & 0.6464 & 0.6432 \\
\hline & $r_{\max }$ & 0.7256 & 0.7045 & 0.6892 & 0.6767 & 0.6664 & 0.6578 & 0.6514 & 0.6463 & 0.6418 & 0.6386 \\
\hline & & \multicolumn{10}{|c|}{ Turbulent rough regime } \\
\hline \multirow[t]{3}{*}{ Plastic } & $r_{\min }$ & 0.7223 & 0.7012 & 0.6858 & 0.6733 & 0.6629 & 0.6543 & 0.6480 & 0.6428 & 0.6383 & 0.6351 \\
\hline & $r_{m}$ & 0.7226 & 0.7014 & 0.6860 & 0.6736 & 0.6632 & 0.6546 & 0.6482 & 0.6431 & 0.6386 & 0.6354 \\
\hline & $r_{\max }$ & 0.7230 & 0.7019 & 0.6865 & 0.6740 & 0.6636 & 0.6550 & 0.6487 & 0.6435 & 0.6390 & 0.6358 \\
\hline \multirow[t]{3}{*}{ Steel } & $r_{\min }$ & 0.7137 & 0.6926 & 0.6773 & 0.6649 & 0.6545 & 0.6460 & 0.6397 & 0.6346 & 0.6301 & 0.6269 \\
\hline & $r_{m}$ & 0.7156 & 0.6944 & 0.6791 & 0.6666 & 0.6563 & 0.6477 & 0.6414 & 0.6363 & 0.6318 & 0.6286 \\
\hline & $r_{\max }$ & 0.7178 & 0.6967 & 0.6813 & 0.6688 & 0.6585 & 0.6499 & 0.6436 & 0.6384 & 0.6339 & 0.6307 \\
\hline \multirow[t]{3}{*}{ Stand. } & $r_{\min }$ & 0.6330 & 0.6100 & 0.5936 & 0.5805 & 0.5696 & 0.5607 & 0.5542 & 0.5489 & 0.5443 & 0.5410 \\
\hline & $r_{m}$ & 0.6413 & 0.6184 & 0.6020 & 0.5888 & 0.5780 & 0.5691 & 0.5625 & 0.5572 & 0.5526 & 0.5493 \\
\hline & $r_{\max }$ & 0.6529 & 0.6301 & 0.6137 & 0.6005 & 0.5897 & 0.5808 & 0.5742 & 0.5689 & 0.5642 & 0.5609 \\
\hline \multirow[t]{3}{*}{ Switch } & $r_{\min }$ & 0.7312 & 0.7106 & 0.6956 & 0.6835 & 0.6734 & 0.6650 & 0.6588 & 0.6538 & 0.6494 & 0.6462 \\
\hline & $r_{m}$ & 0.7307 & 0.7100 & 0.6950 & 0.6828 & 0.6727 & 0.6643 & 0.6581 & 0.6530 & 0.6486 & 0.6455 \\
\hline & $r_{\max }$ & 0.7300 & 0.7093 & 0.6942 & 0.6820 & 0.6718 & 0.6634 & 0.6571 & 0.6521 & 0.6477 & 0.6445 \\
\hline
\end{tabular}


factors with increasing $r_{a}$. Here this indicates a decreasing influence of different material roughness with increased outer pipe radius. The shift is increasing very slightly with SDR since this also means an increase in effective radius. The effect is more significant in turbulent flows than in rough regime turbulent flows because the initial influence of different material roughness is larger in this case.

\section{Comparison to fixed mass flow rates}

Figure 2a shows the results of the optimization with a fixed mass flow rate. The results show a higher optimal dimensionless inner pipe radius for laminar flow types than for turbulent flow types. The laminar flow type optimum is $24 \%$ larger on average for fixed mass flow rates compared to fixed Reynolds numbers. This influence is with 7.1\% smaller for turbulent flow types but still significant.

\section{Approximations}

Equation 37 shows an approximation to calculate the optimal dimensionless inner pipe radius for laminar flows. Approximation has a root mean square error (RMSE) less than 0.0011 . The y axis intercept of 0.5367 is lower compared to Yekoladio with an intercept of 0.683 (Yekoladio et al. 2013). This lower intercept is because Yekoladio considers a constant mass flow rate for optimization instead of a constant Reynolds number. A clear dependency on standard dimension ratio (inner pipe thickness) is evident.

$$
c_{\text {opt }, \operatorname{lam}}=\frac{0.5604}{\mathrm{SDR}}+0.5367
$$

Equation 38 shows an approximation to calculate the optimal inner to outer pipe radius for turbulent flows. The approximation has a root mean square error less than 0.0226 for plastic pipes (switched case) and less than 0.0430 for steel pipes (standard case). RMSE is less than 0.0070 for GHEs with both pipes made from steel and an RMSE of 0.0030 for two plastic pipes.

$$
c_{\text {opt turb }}=\frac{0.6006}{\mathrm{SDR}}+0.6064
$$

Equation 39 shows an approximation to calculate the optimal inner to outer pipe radius for rough regime turbulent flows. The approximation has an RMSE less than 0.0207 if outer and inner pipe are of same material. RMSE is less than 0.0729 for GHEs with an inner pipe of plastic and outer pipe of steel (standard case) and an RMSE of 0.0303 for switched materials. In Table 5 equation parameters for the different cases are shown.

$$
c_{\text {opt,turbr.r. }}=\frac{0.6132}{\mathrm{SDR}}+0.5988
$$

For turbulent flows the intercept of 0.6064 and 0.5988 is as well lower than Nakayamas result of 0.653 (Nakayama and Boucher 1999a). An inner pipe thickness's influence on the result is also evident here. 
Table 5 Approximation of hydraulic results following the scheme $c_{\mathrm{opt}}(\mathrm{SDR})=\frac{m}{\mathrm{SDR}}+b$

\begin{tabular}{|c|c|c|c|c|}
\hline \multicolumn{2}{|l|}{ Case } & \multicolumn{3}{|c|}{ Parameters regression } \\
\hline Material & $r_{a}$ & Slope m & intercept b & RMSE \\
\hline & & Laminar & & \\
\hline \multirow[t]{2}{*}{-} & - & 0.5604 & 0.5367 & 0.0011 \\
\hline & & Turbulent & & \\
\hline \multirow[t]{3}{*}{ Plastic } & $r_{\min }$ & 0.5996 & 0.6093 & 0.0010 \\
\hline & $r_{m}$ & 0.5994 & 0.6093 & 0.0010 \\
\hline & $r_{\max }$ & 0.5992 & 0.6093 & 0.0010 \\
\hline \multirow[t]{3}{*}{ Steel } & $r_{\min }$ & 0.6068 & 0.6105 & 0.0009 \\
\hline & $r_{m}$ & 0.6081 & 0.6118 & 0.0009 \\
\hline & $r_{\max }$ & 0.6099 & 0.6126 & 0.0010 \\
\hline \multirow[t]{3}{*}{ Stand. } & $r_{\min }$ & 0.5954 & 0.5639 & 0.0011 \\
\hline & $r_{m}$ & 0.5935 & 0.5770 & 0.0010 \\
\hline & $r_{\max }$ & 0.5927 & 0.5940 & 0.0010 \\
\hline \multirow[t]{4}{*}{ Switch } & $r_{\min }$ & 0.5959 & 0.6293 & 0.0009 \\
\hline & $r_{m}$ & 0.5997 & 0.6274 & 0.0009 \\
\hline & $r_{\max }$ & 0.6074 & 0.6226 & 0.0009 \\
\hline & & Turbulent & & \\
\hline \multirow[t]{3}{*}{ Plastic } & $r_{\min }$ & 0.6092 & 0.6191 & 0.0009 \\
\hline & $r_{m}$ & 0.6092 & 0.6193 & 0.0009 \\
\hline & $r_{\max }$ & 0.6092 & 0.6198 & 0.0009 \\
\hline \multirow[t]{3}{*}{ Steel } & $r_{\min }$ & 0.6064 & 0.6109 & 0.0009 \\
\hline & $r_{m}$ & 0.6073 & 0.6126 & 0.0009 \\
\hline & $r_{\max }$ & 0.6082 & 0.6147 & 0.0009 \\
\hline \multirow[t]{3}{*}{ Stand. } & $r_{\min }$ & 0.6407 & 0.5238 & 0.0013 \\
\hline & $r_{m}$ & 0.6414 & 0.5321 & 0.0013 \\
\hline & $r_{\max }$ & 0.6412 & 0.5438 & 0.0012 \\
\hline \multirow[t]{3}{*}{ Switch } & $r_{\min }$ & 0.5933 & 0.6306 & 0.0009 \\
\hline & $r_{m}$ & 0.5950 & 0.6298 & 0.0009 \\
\hline & $r_{\max }$ & 0.5973 & 0.6288 & 0.0009 \\
\hline
\end{tabular}

\section{Thermal results}

Figure 3 illustrates that in the laminar case, the total borehole resistance decreases with an increasing dimensionless inner radius $(c)$. This trend is independent of the considered case. Equation 4 shows that an increasing dimensionless inner radius results in an increasing mass flow rate, if $R e_{c}$ is kept constant. Additionally, Eq. 20 shows the ratio between the inner pipe and circular ring Reynolds number, which is constantly decreasing with an increasing dimensionless inner radius $(c)$. This decrease results in lower Reynolds numbers in the inner pipe for larger dimensionless radii $c$. Since lower Reynolds numbers inhibit heat transfer, the thermal short circuit heat flux decreases with increasing dimensionless inner radii $(c)$. Therefore, it is plausible that the thermal performance constantly increases towards $c \approx 1$. Total borehole resistance for turbulent flow scenarios increases with dimensionless inner radius to its maximum at about $c=0.3$. It decreases from there until the minimum is reached close to a dimensionless inner radius of $c=1$. The initial increase in the resistance appears to be due to calculation inaccuracies for low dimensionless inner 


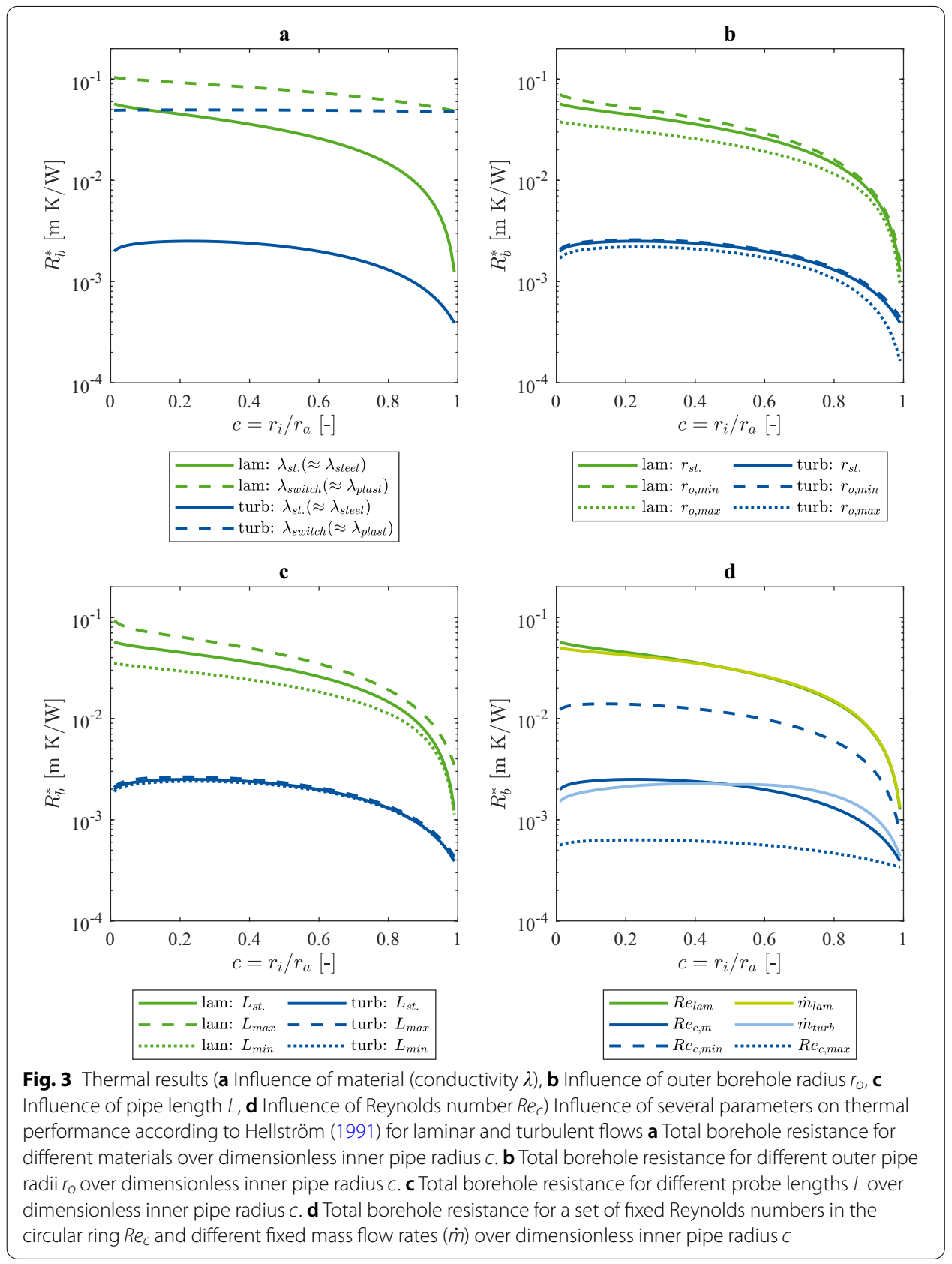

pipe radii in the turbulent case. Even for turbulent cases, the conclusion holds that the greatest possible dimensionless inner radius should be chosen for best thermal performance.

The result for the optimal inner pipe radius agrees with the previous studies by Iry and Rafee (2019) and Zanchini et al. (2010). Hence, the calculations are assumed to be valid.

For both SDR variations, $R_{b}^{*}$ differs on average by less than $0.7 \%$ and at most by $3 \%$ from the standard case. Influence of SDR on the thermal response is therefore neglected in further calculations and not shown in the graphs (see Table 6). 
Table 6 Thermal Results as total borehole resistance $R_{b}^{*}[\mathrm{~mm} \mathrm{K/W]}$ for several scenarios

\begin{tabular}{|c|c|c|c|c|c|c|c|c|c|c|c|c|}
\hline \multirow[t]{2}{*}{$c[-]$} & \multicolumn{4}{|c|}{$\lambda[\mathrm{W} / \mathrm{mK}]$} & \multicolumn{2}{|l|}{$L[\mathrm{~m}]$} & \multicolumn{2}{|c|}{ SDR[-] } & \multicolumn{2}{|l|}{$r_{o}[\mathrm{~m}]$} & \multicolumn{2}{|l|}{$\operatorname{Re}_{c}[-]$} \\
\hline & Stand. & Switch & Plastic & Steel & 100 & 5 & 6 & 41 & $\min$ & $\max$ & $4 \cdot 10^{3}$ & $10^{5}$ \\
\hline & \multicolumn{12}{|l|}{ Laminar } \\
\hline 0.010 & 56.94 & 104.03 & 104.03 & 56.94 & 92.67 & 35.06 & 56.94 & 56.94 & 70.38 & 37.79 & & \\
\hline 0.108 & 49.55 & 96.66 & 96.64 & 49.56 & 71.56 & 31.88 & 49.54 & 49.56 & 58.82 & 34.19 & & \\
\hline 0.206 & 44.81 & 91.94 & 91.90 & 44.85 & 63.43 & 29.32 & 44.78 & 44.83 & 52.58 & 31.36 & & \\
\hline 0.304 & 40.30 & 87.47 & 87.40 & 40.38 & 56.34 & 26.77 & 40.26 & 40.35 & 46.88 & 28.56 & & \\
\hline 0.402 & 35.74 & 82.95 & 82.84 & 35.85 & 49.35 & 24.12 & 35.70 & 35.80 & 41.20 & 25.66 & & \\
\hline 0.500 & 31.01 & 78.25 & 78.11 & 31.16 & 42.23 & 21.34 & 30.97 & 31.09 & 35.38 & 22.62 & & \\
\hline 0.598 & 26.04 & 73.30 & 73.14 & 26.20 & 34.93 & 18.35 & 25.99 & 26.11 & 29.36 & 19.36 & & \\
\hline 0.696 & 20.72 & 68.00 & 67.82 & 20.90 & 27.41 & 15.09 & 20.68 & 20.79 & 23.04 & 15.81 & & \\
\hline 0.794 & 14.96 & 62.24 & 62.05 & 15.14 & 19.66 & 11.42 & 14.91 & 15.01 & 16.37 & 11.82 & & \\
\hline 0.892 & 8.56 & 55.84 & 55.66 & 8.74 & 11.69 & 7.05 & 8.52 & 8.62 & 9.25 & 7.12 & & \\
\hline \multirow[t]{2}{*}{0.990} & 1.25 & 48.53 & 48.35 & 1.43 & 3.47 & 1.13 & 1.22 & 1.32 & 1.57 & 0.92 & & \\
\hline & \multicolumn{12}{|c|}{ Turbulent } \\
\hline 0.010 & 1.99 & 49.09 & 49.09 & 1.99 & 2.08 & 1.90 & 1.99 & 1.99 & 2.07 & 1.70 & 12.25 & 0.56 \\
\hline 0.108 & 2.42 & 49.54 & 49.52 & 2.44 & 2.58 & 2.32 & 2.42 & 2.43 & 2.51 & 2.12 & 13.92 & 0.62 \\
\hline 0.206 & 2.50 & 49.62 & 49.60 & 2.53 & 2.65 & 2.40 & 2.50 & 2.51 & 2.58 & 2.20 & 13.84 & 0.63 \\
\hline 0.304 & 2.48 & 49.61 & 49.58 & 2.51 & 2.61 & 2.38 & 2.48 & 2.49 & 2.56 & 2.18 & 13.30 & 0.63 \\
\hline 0.402 & 2.38 & 49.52 & 49.48 & 2.42 & 2.50 & 2.30 & 2.38 & 2.39 & 2.46 & 2.10 & 12.44 & 0.62 \\
\hline 0.500 & 2.22 & 49.36 & 49.32 & 2.26 & 2.32 & 2.15 & 2.22 & 2.23 & 2.29 & 1.94 & 11.29 & 0.59 \\
\hline 0.598 & 1.99 & 49.13 & 49.09 & 2.03 & 2.07 & 1.94 & 1.99 & 2.00 & 2.06 & 1.73 & 9.86 & 0.56 \\
\hline 0.696 & 1.69 & 48.83 & 48.79 & 1.74 & 1.76 & 1.66 & 1.69 & 1.70 & 1.76 & 1.44 & 8.15 & 0.52 \\
\hline 0.794 & 1.33 & 48.47 & 48.43 & 1.37 & 1.39 & 1.31 & 1.33 & 1.33 & 1.39 & 1.09 & 6.12 & 0.47 \\
\hline 0.892 & 0.90 & 48.04 & 47.99 & 0.94 & 0.94 & 0.89 & 0.89 & 0.90 & 0.95 & 0.66 & 3.70 & 0.41 \\
\hline 0.990 & 0.39 & 47.54 & 47.49 & 0.44 & 0.43 & 0.39 & 0.39 & 0.39 & 0.44 & 0.16 & 0.70 & 0.34 \\
\hline
\end{tabular}

\section{Materials}

Laminar results for the standard case (inner pipe: plastic, outer pipe: steel) differ only slightly from results where the inner pipe material is changed to steel as well (average difference of $1.8 \%$ ). In the switched case (outer pipe made from plastic and an inner pipe made of steel), results coincide in good approximation to plastic results as the material for both pipes. Generally, when the outer pipe consists of plastic, the total borehole resistance is more than $83 \%$ higher than in the standard case due to lower thermal conductivity. These findings suggest that the influence of outer pipe material on the thermal response is far greater than the influence of inner pipe material. Only the standard case and the case with switched materials are plotted in Fig. 3a, because of good readability. In turbulent flows, an outside pipe of plastic leads to an approximately 35 times higher borehole resistance.

\section{Borehole radius}

An increased borehole radius in laminar flows reduces the total borehole resistance by $27 \%$. A decrease in borehole radius results in a $16 \%$ higher total borehole resistance on average (see Fig. 3b). In turbulent flow cases, borehole radius has a less important impact on total borehole resistance ( $-19 \%$ to $4.6 \%)$ than in laminar flows. Increasing 
the outer borehole radius is beneficial for all flow types. This increase was evident since a larger radius also means a larger heat transfer area per meter borehole.

\section{Borehole length}

For a borehole length of $100 \mathrm{~m}$ total borehole resistance is on average 52\% higher and for a length of $5 \mathrm{~m}$ on average $29 \%$ lower for laminar case (see Fig. 3c). This result is reasonable since total borehole resistance is relative to the unit length of the borehole. The thermal yield increases with borehole length, but not linearly, because on the other hand, heat losses from up-to downstream per unit length of the borehole increase, too (see Eq. 31). This trend is due to larger temperature differences between inner and outer pipe for greater borehole length. For turbulent flows, the trend is the same. However, with an average difference of $+5.5 \% /-2.8 \%$ borehole length has a significantly smaller influence than in laminar flows.

\section{Flow type}

Increasing the Reynolds number and therefore pushing the fluid flow towards turbulent flow improves the thermal response significantly. Turbulent cases have lower total borehole resistances in comparison to the total borehole resistance for the laminar case (by $710 \%$, in average) (see Fig. 3d). Even when the flow is already turbulent, an increase in Reynolds number still yields improvements on average $\approx 65 \%$ better results for an increase in Reynolds number of one order of magnitude. This improvements outweigh improvements by an increased borehole radius $(\approx 18 \%$ better results for a radius increase of $320 \%$ ) or shorter pipes ( $\approx 3 \%$ better results for $1 / 4$ of original pipe length) by far. Hence, one of the major influences on thermal performance is the flow type in the probe. The curve variation reduces when the Reynolds number increases, suggesting that the performance becomes independent from the inner dimensionless radius and more independent on materials.

\section{Comparison to fixed mass flow rates}

Figure $3 \mathrm{~d}$ shows the results of the optimization with a fixed mass flow rate. The results show a similar trend as for the optimization with a fixed Reynolds number. Due to the chosen design flow rate by $c$ of 0.5 the curves cross at this point. Before the total borehole resistance is lower (max. 13\% for laminar, max. 24\% for turbulent flow types). Afterwards, it is higher (max. 5\% for laminar, max. $12 \%$ for turbulent flow types). This influence is due to the change in Reynolds number. In general, the impact is less significant compared to the hydraulic optimum. The difference is on average $1.7 \%$ for laminar and $4 \%$ for turbulent flow types. The optimal results stay the same.

\section{Exergetic results}

A combination of hydraulic and thermal calculations using net-exergetic optimization will be shown. Figure 4a shows the deviation of optimal dimensionless inner pipe radius in net-exergy optimization $\left(c_{\mathrm{opt}}\right.$,exergy $)$ from the optimum in hydraulic optimization. It is plotted over different SDR values and several thermal ground resistances $\left(R_{g}\right)$ for laminar and turbulent flows. Figure $4 \mathrm{~b}$ visualizes the exergetic optimum deviation from the hydraulic optimum. It is plotted over ground resistance $R_{g}$ for different temperature 

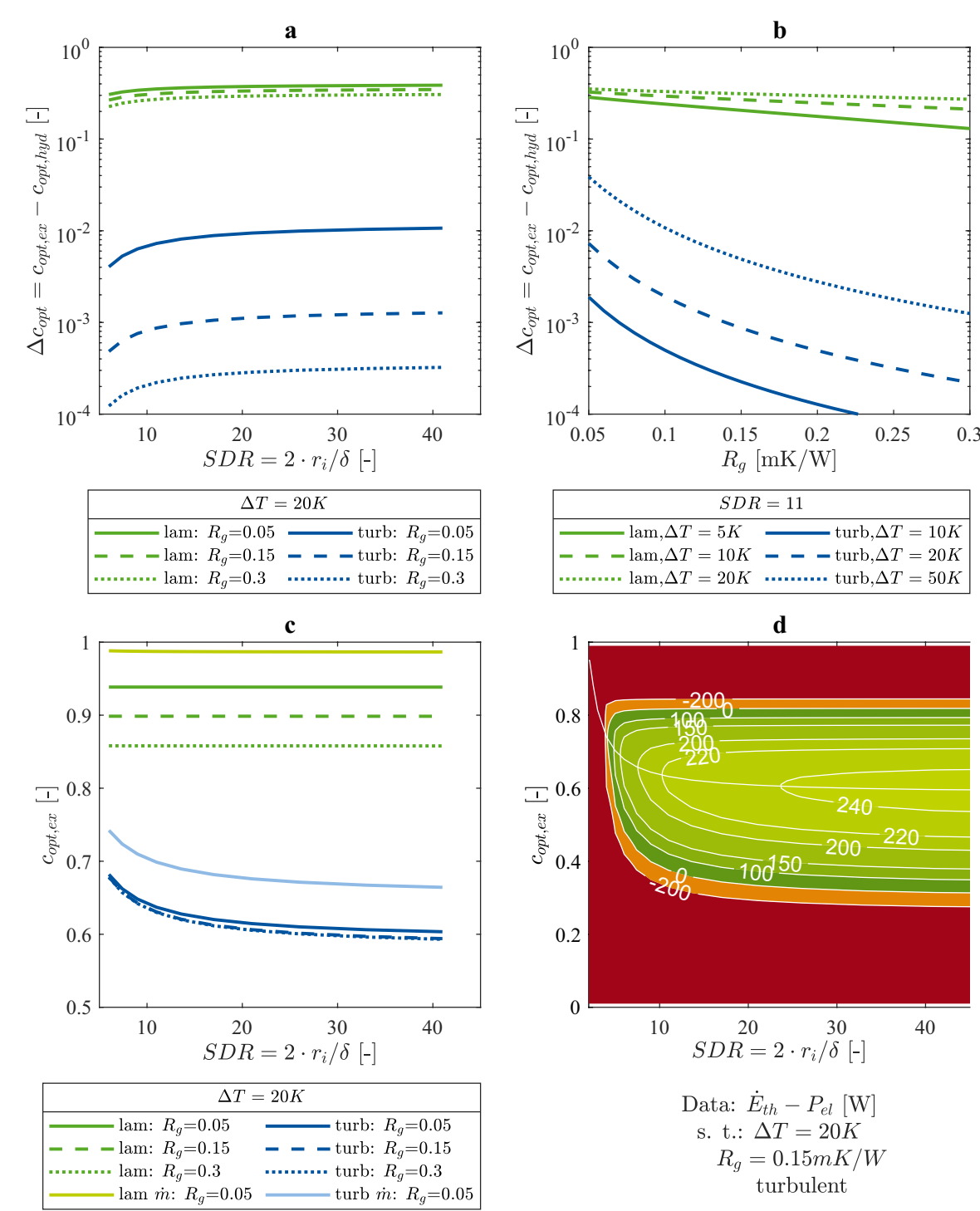

Data: $\dot{E}_{t h}-P_{e l}[\mathrm{~W}]$

s. t.: $\Delta T=20 K$

$R_{g}=0.15 \mathrm{mK} / W$

turbulent

Fig. 4 Exergetic results (a Influence of SDR \& ground resistance, $\mathbf{b}$ Influence of temperature difference, $\mathbf{c}$ Exergetic optimum, d Exergetic results) for laminar and turbulent flows a Change of optimal inner to outer pipe ratio $\left(C_{\mathrm{opt}}\right)$ compared to hydraulic results over Standard Dimension Ratio (SDR) and ground resistance $\left(R_{q}\right) \cdot \mathbf{b}$ Change of optimal inner to outer pipe ratio $\left(c_{\mathrm{opt}}\right)$ over ground resistance $\left(R_{q}\right)$ and temperature difference $(\Delta T)$. c optimal inner to outer pipe ratio ( $\left.c_{\text {opt }}\right)$ over Standard Dimension Ratio (SDR) and ground resistance $\left(R_{g}\right)$ for fixed Reynolds numbers and fixed mass flow rates $(\dot{m})$. $\mathbf{d}$ Exemplary distribution of objective function over the range of $c$ and determined optimum $c_{\text {opt }}$

levels for laminar and turbulent flows. It is evident that in all cases, the optimal dimensionless inner pipe radius increases and therefore moves from the hydraulic optimum towards the thermal optimum of $c_{\mathrm{opt}}=1$. The most significant change in $c_{\mathrm{opt}}$ occurs for laminar flows with very low thermal ground resistance. Reducing ground resistance moves the optimum closer towards the thermal optimum since thermal yields increase.

For laminar flows, $c_{\mathrm{opt}}$ increases significantly more to the thermal optimum than for turbulent flows. One explanation is that in laminar flows, the hydraulic effort is by far less than in turbulent flows. Hence the hydraulic term in laminar flows has a smaller 
effect on net exergy transfer than turbulent flows shifting the optimal dimensionless inner pipe radius more towards the thermal optimum. Figure $4 \mathrm{c}$ even shows that $c_{\mathrm{opt}}$ in the laminar case is shifted beyond the initially higher $c_{\text {opt }}$ values in the turbulent case. Another indicator for the large thermal influence compared to the small influence of hydraulics on the laminar optimization result is that $c_{\mathrm{opt}}$ is virtually independent of SDR in exergy optimization for the considered values. This implies that changing SDR has no more significant influence on the overall result for values of SDR greater than 10 (pipe thickness $\left.\delta<r_{i} / 5\right)$.

For turbulent flows, the dependency on SDR also reduces since thermal results have proven to be independent of SDR. Nonetheless, the shift of the thermal optimum is smaller in turbulent cases than in laminar cases, suggesting that hydraulics are more important for the exergetic optimum.

The inlet temperature difference to ground temperature also has a strong influence on $c_{\mathrm{opt}}$, as shown in Fig. 4b: The greater the temperature difference, the greater the shift towards the thermal optimum. This shift is reasonable since the temperature does not influence the hydraulic optimum. Therefore, greater temperature differences only increase the thermal exergy, resulting in a higher thermal optimum weighting. It is also clearly visible that the shift's size decreases with increasing ground resistance because this inhibits thermal processes.

Figure $4 \mathrm{~d}$ visualizes the optimal solution for one scenario and the solution space distribution. It is shown that the optimal inner to outer pipe ratio $(c)$ is following the best exergetic results for different standard dimensioning ratios SDR. Furthermore, exergy flux is increasing with increasing SDR. In this case, there also is a lower bound on feasible SDR values at approximately 4 since otherwise, no exergy flux is realized.

Figure 4c shows the results of the optimization with a fixed mass flow rate. The results show a significant difference to the optimization with fixed Reynolds numbers for both flow types. For turbulent flow types, the results differ on average by $11 \%$ and for laminar flow types by $9 \%$ due to the difference in the hydraulic-optimal solution. For laminar flow types, the approach of fixed Reynolds numbers leads to a significantly more net exergy difference (90\% more net-exergy difference for an SDR of 11). For turbulent flow types, it is also significant (17\% more net-exergy difference for an SDR of 11).

For practical applications, the results can be generalized. Geothermal probes are operated based on seasonal changes and often used as seasonal storages as well. In most cases, environmental conditions correspond to conditions after several hours of continuous operation. Even when there has been no operation overnight/day, environmental conditions do not fully regenerate to undisturbed conditions. Hence, ground resistance can be assumed to be quite high for these periods (assume $R_{g}>0.15 \mathrm{~m} \mathrm{~K} / \mathrm{W}$ ). In practice, one also aims to keep temperature difference to a ground temperature low and definitely below $50 \mathrm{~K}$. If we assume that the temperature difference does not exceed $20 \mathrm{~K}$ in practical operations, only two cases remain:

For laminar flow, the optimal dimensionless inner pipe radius is about 55\% larger when considering exergy than the pure hydraulic result. The optimal radius, in this case, depends no longer on pipe thickness but solely on Reynolds number and ground resistance. However, laminar flow is disadvantageous regarding the probe's thermal behaviour (see section thermal calculation) and therefore not recommended as a design point. 
In turbulent flow, the optimal dimensionless inner pipe radius is deviating only about $0.2 \%$ from the hydraulic optimum. The influence of thermal behaviour on the optimal inner pipe radius is small for the design point. Conclusively, the best case for designing a geothermal probe is ensuring turbulence and choosing the inner pipe radius solely based on the hydraulic optimum. If the optimum is between two available pipe sizes, it is recommendable to choose the bigger pipe to enhance thermal performance during start-up periods.

\section{Conclusion}

The hydraulic optimum is an inner to outer pipe ratio of 0.54 for laminar flows and 0.6 for turbulent flows. These values neglect the influence of inner pipe thickness. A netexergetic comparison of hydraulic and thermal impacts has identified a predominant impact of hydraulic losses for non-ideal thermal turbulent flow conditions. Calculations based on Hellström have shown that the gap between the inner and outer pipe should be as small as possible from a purely thermal perspective.

Comparing the new approach with the fixed mass flow rate approach has shown a significant difference in the hydraulic-optimal solution. It has no impact on the thermal optimum. The impact on the net-exergetic optimum of fixed Reynolds numbers is significant. Here, the new approach results in lower dimensionless inner pipe radii $(-9 \%$ for laminar and $-11 \%$ for turbulent flow types) and more net-exergetic difference $(+17 \%$ for laminar and $+90 \%$ for turbulent flow types). Not only does the approach presented more accurately reflect reality, but it also leads to better yields, especially in regions where hydraulics dominate. Conclusively, we recommend the new approach for further research.

The main conclusions are:

- For turbulent flow conditions, hydraulic loss is more important than thermal gain.

- The approach with a constant Reynolds number in the circular ring leads to significantly different hydraulic results compared to an approach with a constant mass flow rate.

- The optimal hydraulic inner to outer pipe radius ratio for turbulent flows is about 0.61 with an increase of $\frac{0.60}{\text { SDR }}$.

- The net exergetic optimum for turbulent flows with low heat fluxes corresponds to the hydraulic optimum in a good approximation.

For the standard case with a steel outer pipe radius of 75 (inner radius)/85 mm (outer radius) and an inner plastic pipe with an SDR value of 11, this leads to an optimal inner pipe radius of $49.58 \mathrm{~mm}$ (See Eq. 38). If this exact diameter is not available, the next larger one should be chosen. For example, a PE-100 RC pipe with a radius of $55 \mathrm{~mm}$ can be an option.

\footnotetext{
Abbreviations

$\alpha_{i}$ : Convective heat transfer coefficients of the inner pipe $\left(\mathrm{W} /\left(\mathrm{m}^{2} \mathrm{~K}\right)\right) ; \alpha_{0}$ : Convective heat transfer coefficients of the outer circular ring $\left(\mathrm{W} /\left(\mathrm{m}^{2} \mathrm{~K}\right)\right)$; $c$ : Dimensionless inner radius $(-) ; c_{p}$ : Heat capacity $(\mathrm{J} / \mathrm{kg} \mathrm{K}) ; c_{m}$ : Dimensionless mean inner radius (-); $c_{m, o p t}$ : Mean optimal inner to outer pipe ratio $(-) ; C_{\text {opt: }}$ Optimal inner to outer pipe ratio $(-) ; \delta$ : Inner pipe thickness $(\mathrm{m}) ; \Delta p_{\text {coax: }}$ Hydraulic loss of a coaxial heat exchanger $(\mathrm{Pa}) ; \Delta T:$ Inlet temperature difference above earth
} 


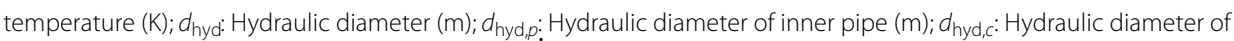
circular ring (m); K: Dimensionless power factor (-); $\dot{Q}_{g e o:}$ Geothermal heat flux (W); $k$ : Surface roughness (m); $k_{a}$ : Surface roughness of outer pipe $(m) ; k_{c}$ : Medium surface roughness for the circular ring $(m) ; k_{p}$ : Surface roughness of inner pipe $(m) ;$ : Length of geothermal pipe $(m) ; \lambda$ : Thermal conductivity $(W /(m K)) ; \lambda_{c}:$ Thermal conductivity of outer pipe $(\mathrm{W} /(\mathrm{m} \mathrm{K})) ; \lambda_{p}$ : Thermal conductivity of inner pipe $(\mathrm{W} /(\mathrm{m} \mathrm{K})) ; \dot{m}$ : Mass flow rate $(\mathrm{kg} / \mathrm{s}) ; v$ : Kinematic viscosity $\left(\mathrm{m}^{2} / \mathrm{s}\right) ; \mathrm{Nu}$ :

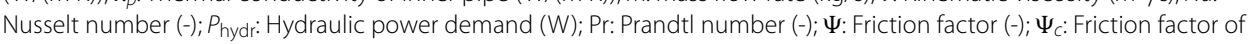
circular ring (-); $\Psi_{p}$ : Friction factor of inner pipe (-); $r_{a}$ : Inner radius of outer pipe $(\mathrm{m}) ; r_{i}$ : Outer radius of inner pipe $(\mathrm{m}) ; \bar{r}_{j}$ : Inner radius of the inner pipe $(\mathrm{m}) ; r_{0}$ : Outer pipe radius of outer pipe $(\mathrm{m}) ; R_{a}:$ Internal borehole resistance $(\mathrm{m} \mathrm{K} / \mathrm{W}) ; R_{b}$ : Borehole resistance ( $\mathrm{m} \mathrm{K} / \mathrm{W}) ; R_{b}^{*}$ :Total borehole resistance $(\mathrm{m} \mathrm{K} / \mathrm{W}) ; R_{g}$ : Thermal ground resistance $(\mathrm{m} \mathrm{K} / \mathrm{W})$; Re: Reynolds number (-); Rec: Reynolds number of circle ring (-); Rep: Reynolds number of inner pipe (-); $\rho$ : Fluid density $\left(\mathrm{Kg} / \mathrm{m}^{3}\right)$; RMSE: Root Mean Square Error (-); SDR: Standard Dimension Ratio (-); SQP: Sequential Quadratic Programming; $T_{e}$ : Earth temperature $\left({ }^{\circ} \mathrm{C}\right) ; T_{\text {in }}$ : Inlet temperature $\left({ }^{\circ} \mathrm{C}\right) ; T_{\text {out }}$ : Outlet temperature $\left({ }^{\circ} \mathrm{C}\right) ; v$ : Fluid velocity $(\mathrm{m} / \mathrm{s}) ; v_{c}$ : Fluid velocity in circular ring $(\mathrm{m} / \mathrm{s}) ; v_{p}$ : Fluid velocity in inner pipe $(\mathrm{m} / \mathrm{s}) ; \dot{V}:$ Volume flow rate $\left(\mathrm{m}^{3} / \mathrm{s}\right)$.

\section{Acknowledgements}

The research project IGF 28EWN / P1285"Integral solutions for plus energy buildings 2.0 in lightweight steel construction" from the Research Association for steel Application (FOSTA), Düsseldorf, is supported by the Federal Ministry of Economic Affairs and Energy through the German Federation of Industrial Research Associations (AiF) as part of the programme for promoting industrial cooperative research (IGF) on the basis of a decision by the German Bundestag. The project is carried out at Solar Institute Jülich.

\section{Authors' contributions}

TB and MH worked on data collection, calculations and wrote the manuscript. BD and MK directed the project, providing ideas and goals as well as logistical support. VR provided useful comments and insights to improve the conceptual models. All authors proofread the manuscript and provided their comments and insights. All authors read and approved the final manuscript.

\section{Funding}

Open Access funding enabled and organized by Projekt DEAL. This research was carried out within the project"Integral solutions for plus energy buildings 2.0 in lightweight steel construction" from the Research Association for steel Application (FOSTA), funded by the German Federal Ministry for Economic Affairs and Energy (BMWi). Open access funding provided by Projekt DEAL.

\section{Availability of data and materials}

The data used to support the findings of this study are included within the article.

\section{Declarations}

Competing interests

The authors declare that they have no competing interests.

\section{Author details}

${ }^{1}$ FH Aachen, Bayernallee 9, 52066 Aachen, Germany. ${ }^{2}$ Solar Institut Jülich, FH Aachen, Heinrich-Mußmann-Str. 5, 52428 Jülich, Germany. ${ }^{3}$ Lehr- und Forschungsgebiet Nachhaltigkeit im Metallleichtbau, RWTH Aachen, Mies-van-der-Rohe-Straße 1, 52074 Aachen, Germany.

Received: 18 January 2021 Accepted: 23 June 2021

Published online: 26 July 2021

\section{References}

AM Online Projects Germany climate: weather by month for Germany; 2021. https://en.climate-data.org/europe/ germany-232/.

Alibaba M, Pourdarbani R, Hasan Khoshgoftar Manesh M, Herrera-Miranda I, Gallardo-Bernal I, Hernández-Hernández $J$ L. Conventional and advanced exergy-based analysis of hybrid geothermal-solar power plant based on orc cycle. Appl Sci. 2020;10(15):5206. https://doi.org/10.3390/app10155206.

Alimonti C, Conti P, Soldo E. Selecting the optimal use of the geothermal energy produced with a deep borehole heat exchanger: exergy performance. Proceedings. 2020;58(1):20. https://doi.org/10.3390/WEF-06912.

Boggs PT, Tolle JW. Sequential quadratic programming for large-scale nonlinear optimization. J Comput Appl Math. 2000;124(1-2):123-37. https://doi.org/10.1016/S0377-0427(00)00429-5.

DIN (2011) En 12201-2: plastics piping systems for water supply, and for drainage and sewerage under pressurepart 2: pipes.

Daras NJ. Applications of mathematics and informatics in military science, vol 71. Springer, New York, New York, NY, 2012. https://doi.org/10.1007/978-1-4614-4109-0.

Gashti EHN, Uotinen VM, Kujala K. Numerical modelling of thermal regimes in steel energy pile foundations: a case study. Energy Build. 2014;69:165-74. https://doi.org/10.1016/j.enbuild.2013.10.028.

Gehlin S. Thermal response test: method development and evaluation: thermal response test: method development and evaluation. Doctoral thesis, Luleå University of Technology, Luleå; 2002. http://www.diva-portal.org/smash/ record.jsf?pid=diva2\%3A991442\&dswid=6936. 
Hellström G Ground heat storage: Thermal analyses of duct storage systems. Doctoral thesis, Lund University, Lund, 1991; http://portal.research.lu.se/portal/en/publications/ground-heat-storage--thermal-analyses-of-duct-storage-syste ms(f60847df-a806-4b3d-9788-ca21b1d0aa2f).html.

Hoback AS, Truman KZ. Least weight design of steel pile foundations. Eng Struct. 1993;15(5):379-85. https://doi.org/10. 1016/0141-0296(93)90041-2.

Huber A. Calculation of borehole heat exchangers: software manual. 2018; http://www.hetag.ch/publikationen.html.

Iry S, Rafee R. Transient numerical simulation of the coaxial borehole heat exchanger with the different diameters ratio. Geothermics. 2019;77:158-65. https://doi.org/10.1016/j.geothermics.2018.09.009.

Kratz AP, Macintire HJ, Gould RE. Flow of liquids in pipes of circular and annular cross-sections; 1931. https://www.ideals, illinois.edu/bitstream/handle/2142/4352/engineeringexperv00000i00222.pdf? sequence $=3$.

Mat. Glykosol n: Heat transfer fluid on basis of monoethylene glycol for technical applications; 2016. https://prokuehlsole. de/en/products/download-data-sheets.

Mistry M, Misener R. Optimising heat exchanger network synthesis using convexity properties of the logarithmic mean temperature difference. Comput Chem Eng. 2016;94:1-17. https://doi.org/10.1016/j.compchemeng.2016.07.001.

Moody LF, Princeton NJ. Friction factors for pipe flow. Trans ASME. 1944;66:671-84.

Nakayama Y, Boucher RF. Introduction to fluid mechanics. Butterworth Heinemann, Oxford and Boston; 1999a. http:// search.ebscohost.com/login.aspx?direct=true\&scope $=$ site\&db=nlebk\&db=nlabk\&AN=211419.

Nakayama Y, Boucher RF. Introduction to fluid mechanics. Butterworth Heinemann, Oxford and Boston; 1999b. https:// katalog.ub.uni-heidelberg.de/cgi-bin/titel.cgi?katkey=9907318.

Pro. Constrained nonlinear optimization algorithms; 2019. https://de.mathworks.com/help/optim/ug/constrained-nonli near-optimization-algorithms.html.

Reger V, Kuhnhenne M, Ebbert T, Hachul H, Blanke T, Döring B. Nutzung erneuerbarer energien durch thermische aktivierung von komponenten aus stahl. Stahlbau. 2020;89(6):512-9. https://doi.org/10.1002/stab.202000031.

Reger V, Kuhnhenne M, Hachul H, Döring B, Ebbert T, Blanke T, Göttsche J. Plusenergiegebäude 2.0 in stahlleichtbauweise. Stahlbau. 2019;88(6):522-8. https://doi.org/10.1002/stab.201900034.

VDI. Thermal use of the underground: fundamentals, approvals, environmental aspects; 2010. https://www.vdi.de/richt linien/details/vdi-4640-blatt-1-thermische-nutzung-des-untergrunds-grundlagen-genehmigungen-umweltaspekte. VDI eV, VDI Heat Atlas. Springer, Berlin Heidelberg, Berlin, Heidelberg; 2010. https://doi.org/10.1007/978-3-540-77877-6. White FM. Fluid mechanics. 7th ed. New York, NY: McGraw-Hill; 2011.

Yekoladio PJ, Bello-Ochende T, Meyer JP. Design and optimization of a downhole coaxial heat exchanger for an enhanced geothermal system (egs). Renew Energy. 2013;55:128-37. https://doi.org/10.1016/j.renene.2012.11.035.

Zanchini E, Lazzari S, Priarone A. Improving the thermal performance of coaxial borehole heat exchangers. Energy. 2010;35(2):657-66. https://doi.org/10.1016/..energy.2009.10.038.

\section{Publisher's Note}

Springer Nature remains neutral with regard to jurisdictional claims in published maps and institutional affiliations.

\section{Submit your manuscript to a SpringerOpen ${ }^{\circ}$ journal and benefit from:}

- Convenient online submission

- Rigorous peer review

- Open access: articles freely available online

- High visibility within the field

- Retaining the copyright to your article

Submit your next manuscript at $>$ springeropen.com 